\title{
A study on effect of outsourcing on cost reduction: A case study of tile industry
}

\author{
Amir Reza Shirzadeh*, Seyed Abdollah Heydariyeh and Mohammad Hemmati
}

Department of Industrial Management, Semnan Branch, Islamic Azad University, Semnan, Iran

\begin{tabular}{|c|c|}
\hline CHRON I C LE & A B S T R A C T \\
\hline $\begin{array}{l}\text { Article history: } \\
\text { Received Feb 28, } 2013 \\
\text { Received in revised format } \\
19 \text { September } 2013 \\
\text { Accepted } 23 \text { October } 2013 \\
\text { Available online } \\
\text { November } 202013 \\
\text { Keywords: } \\
\text { Outsourcing } \\
\text { Inventory } \\
\text { Structural equation modeling } \\
\text { Tile industry }\end{array}$ & $\begin{array}{l}\text { During the past few decades, many organizations have attempted to reduce their costs through } \\
\text { outsourcing of non-value added activities. This paper presents an empirical investigation to find } \\
\text { important factors on reducing production expenses through outsourcing activities. The proposed } \\
\text { study of this paper designs a questionnaire in Likert scale consists of } 19 \text { questions and } \\
\text { distributes it among some experts. Using structural equation modeling, the study investigates } \\
\text { different variables and the results indicate that outsourcing could reduce the production cost } \\
\text { through time, inventory and human resources. The implementation of Freedman for ranking } \\
\text { these factors indicate that time played the most influential factor followed by inventory and } \\
\text { human resources. The results of structural equation modeling indicate that there are some } \\
\text { positive and meaningful relationship between human capital and cost }(\beta=0.78, \mathrm{t}-\mathrm{value}=9.38) \text {, a } \\
\text { positive and meaningful relationship between inventory and cost }(\beta=0.81, \mathrm{t}-\mathrm{value}=10.54) \text { and a } \\
\text { positive and meaningful relationship between time and cost }(\beta=0.89, \mathrm{t}-\mathrm{value}=11.26) \text {. }\end{array}$ \\
\hline
\end{tabular}

\section{Introduction}

During the past few decades, many organizations have attempted to reduce their costs through outsourcing non-value added activities (Arnold, 2000; Lee et al., 2003). Outsourcing plays essential role on the success of organizations and when applied properly, it has proven to be cost efficient. Many large-scale organizations prefer to outsource many of their activities in an attempt to keep their business unit agile (Maskell et al., 2007). Outsourcing helps organizations handle any possible financial turmoil more easily (Barthelemy, 2003; Gay \& Essinger, 2000). Gilbert et al. (2006) explored production and outsourcing decisions for two Original Equipment Manufacturers (OEMs) who had the opportunities to invest in reducing the manufacturing expenses. They explored the role that an external supplier(s) could play in dampening competition between the OEMs when there were opportunities to invest in cost reduction. In particular, they characterized the conditions under which a supplier could profitably enter the market by inducing the OEMs to outsource production.

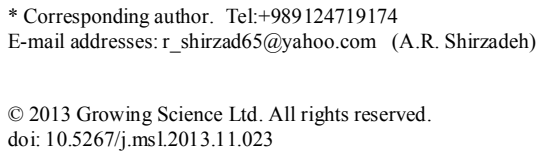


In some cases, outsourcing could create unwelcome consequences such as shortage on inventory, low quality products, etc. and it is necessary to take into account all possible issues (Earl, 2012). Bahli and Rivard (2003) discussed the information technology outsourcing risk by looking into a transaction cost and agency theory-based perspective. Kim (2003) investigated dynamic outsourcing to contract manufacturers with different capabilities of reducing the supply cost.

There are literally various types of outsourcing such as human resource outsourcing (Greer et al., 1999), information technology outsourcing (Rao et al., 1996; Barthelemy \& Geyer, 2001) and it is necessary to detect all drivers and barriers for properly accomplishing this task (Lau \& Zhang, 2006).

\section{The proposed study}

This paper presents an empirical investigation to find important factors on reducing production expenses through outsourcing activities. The proposed study of this paper designs a questionnaire in Likert scale consists of 19 questions and distributes it among some experts in one of Iranian tile industry. The proposed study of this paper considers the following hypotheses,

1. There is a meaningful relationship between outsourcing of activities and inventory expenses.

2. There is a meaningful relationship between outsourcing of activities and time.

3. There is a meaningful relationship between outsourcing of activities and human capital.

4. There is a meaningful relationship between inventory and cost reduction.

5. There is a meaningful relationship between time and cost reduction.

6. There is a meaningful relationship between human capital and cost reduction.

The sample size of the study is calculated as follows,

$N=Z_{\alpha / 2}^{2} \frac{p \times q}{e^{2}}$,

where $N$ is the sample size, $p=1-q$ represents the probability, $z_{\alpha / 2}$ is CDF of normal distribution and finally $\varepsilon$ is the error term. For our study we assume $p=0.5, z_{\alpha / 2}=1.96$ and $e=0.05$, the number of sample size is calculated as $N=98$.

\subsection{Personal characteristics of the participants}

In our survey, 97 of the surveyed people were married and only one person was single. Fig. 1 demonstrates other personal characteristics of the participants in terms of educational background and job experiences.

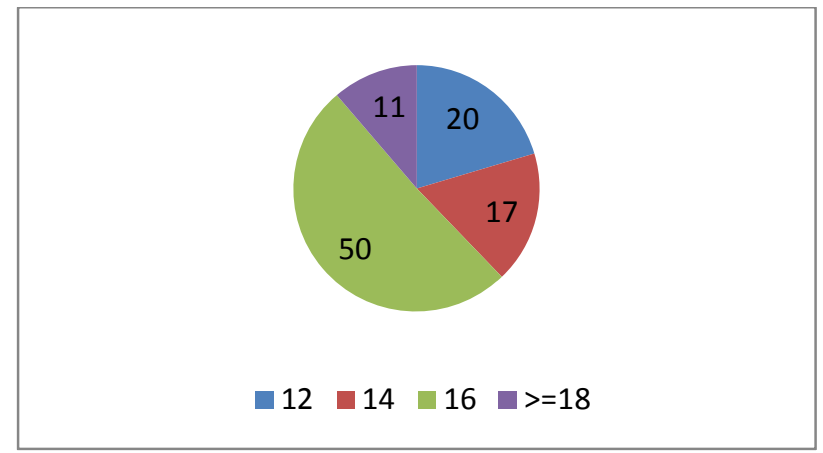

Years of educations

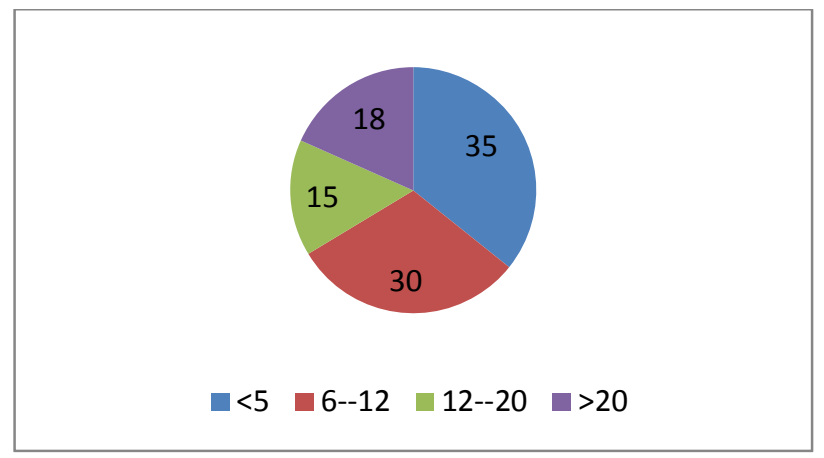

Years of Job experiences

Fig. 1. Personal characteristics of the participants 
As we can observe from Fig. 1, most participants hold, at least, a bachelor of science and at least 5 years of job experiences.

\subsection{Basic descriptive statistics}

We now consider some basic statistics of the participants in terms of mean and standard deviation given in Table 1 as follows,

Table 1

The summary of some basic statistics

\begin{tabular}{|c|c|c|c|c|}
\hline Question & Number & Mean & Standard deviation & Variance \\
\hline$q 1$ & 98 & 2.8214 & .81892 & .671 \\
\hline q2 & 98 & 2.7143 & .65868 & .434 \\
\hline $\mathrm{q} 3$ & 98 & 2.9857 & .74447 & .554 \\
\hline $\mathrm{q} 4$ & 98 & 2.7857 & 1.03126 & 1.063 \\
\hline q5 & 98 & 3.0370 & .93978 & .883 \\
\hline q6 & 98 & 2.8400 & .85049 & .723 \\
\hline q7 & 98 & 2.9259 & 1.07152 & 1.148 \\
\hline q8 & 98 & 2.4444 & .89156 & .795 \\
\hline q9 & 98 & 2.6429 & .98936 & .979 \\
\hline q10 & 98 & 2.6071 & 1.10014 & 1.210 \\
\hline q11 & 98 & 3.0000 & .98131 & .963 \\
\hline q12 & 98 & 3.2593 & .98421 & .969 \\
\hline q13 & 98 & 2.6071 & 1.06595 & 1.136 \\
\hline q14 & 98 & 2.6786 & .98333 & .967 \\
\hline q15 & 98 & 2.6429 & .98936 & .979 \\
\hline q16 & 98 & 2.9259 & .95780 & .917 \\
\hline q17 & 98 & 2.7692 & .95111 & .905 \\
\hline q18 & 98 & 2.9259 & .67516 & .456 \\
\hline q19 & 98 & 3.0370 & 64935 & .422 \\
\hline
\end{tabular}

\subsection{Normality test}

The first step to examine different hypotheses of the survey is to make sure the data are normally distributed using Kolmogorov-Smirnov Z, which is calculated as 0.401 and it means the data are indeed normally distributed.

\subsection{Correlation ratio}

We first examine all hypotheses of the survey based on Pearson correlation ratio. Table 2 demonstrates the summary of correlation ratio.

Table 2

The summary of Pearson correlation

\begin{tabular}{lccc}
\hline Hypothesis & correlation & Sig. & Result \\
\hline 1. The effect of outsourcing on cost reduction & 0.49 & 0.000 & Confirmed \\
2. The effect of time on cost reduction & -0.89 & 0.000 & Confirmed \\
3. The effect of inventory on cost reduction & -0.81 & 0.000 & Confirmed \\
\hline 4. The effect of human capital on cost reduction & 0.78 & 0.000 & Confirmed \\
5. The effect of outsourcing on time & -0.75 & 0.000 & Confirmed \\
6. The effect of outsourcing on Human capital & 0.72 & 0.000 & Confirmed \\
7. The effect of outsourcing on inventory & -0.69 & 0.000 & Confirmed \\
\hline
\end{tabular}

As we can observe from the results of Table 2, all hypotheses of the survey have been confirmed and the sign of correlation ratios are consistent with our expectations. 


\section{The results}

In this section, we present details of the implementation of stepwise regression as well as structural equation modeling.

\subsection{The results of regression analysis}

The results of regression analysis is summarized as follows,

$$
\begin{aligned}
& \text { Cost reduction }=1.358-0.247 \text { Outsourcing }+\varepsilon_{\mathrm{i}} \\
& \begin{array}{l}
\text { t-student } \\
\text { F-value }=5.30312 .931
\end{array} \quad \text { Adjusted } \mathrm{R}^{2}=0.267
\end{aligned}
$$

As we can observe from Eq. (2), an increase of one percent in outsourcing could reduce the cost of production by -0.247 percent. We have performed Freedman test to rank the relative importance of different components. In our survey, time is number one priority $(\mathrm{r}=4.31)$ followed by inventory (2.84) and human capital (1.65).

\subsection{Structural equation modeling}

Structural equation modeling is another useful technique for measuring the impact of outsourcing on cost reduction. We first investigate the impact of each individual factor including human capital, inventory and time.

\subsubsection{The effect of human capital}

Human capital is the first variable, which is influenced by outsourcing and Fig. 3 demonstrates the results of our findings as follows,

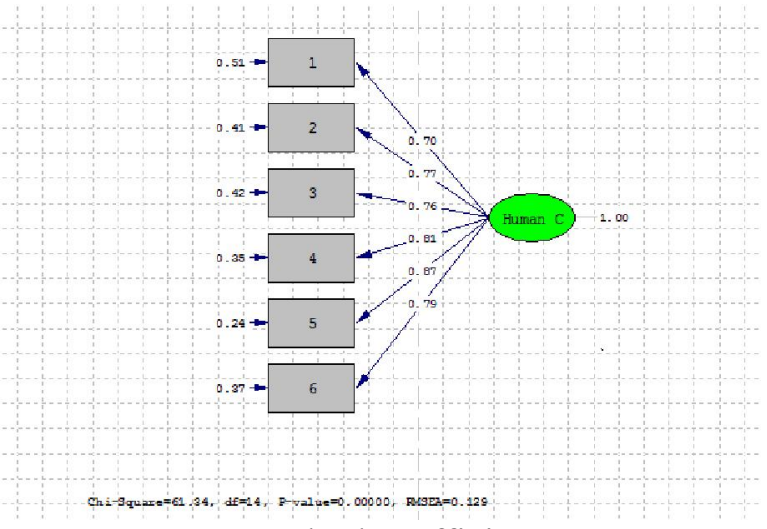

Standard coefficients

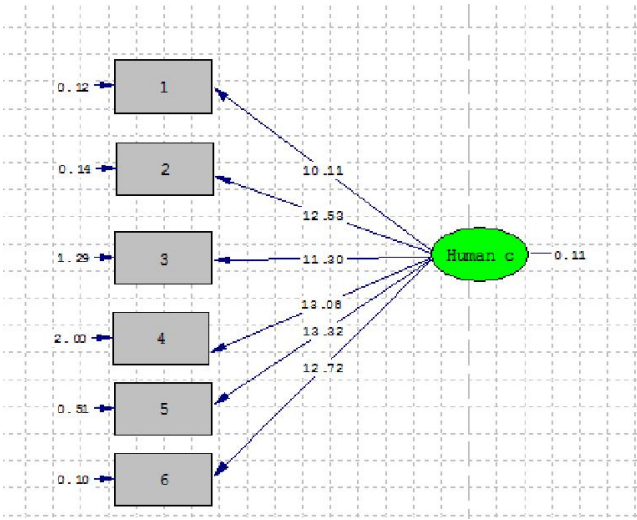

t-student values

Fig. 3. The results of outsourcing on human capital

As we can observe from the results of Fig. 3, all coefficients of the survey are statistically significant and t-student values are meaningful for all questions. Therefore, we can confirm the effect of human capital.

\subsubsection{The effect of Inventory}

Inventory is the second variable in our survey and Fig. 4 shows details of our survey on this variable. 


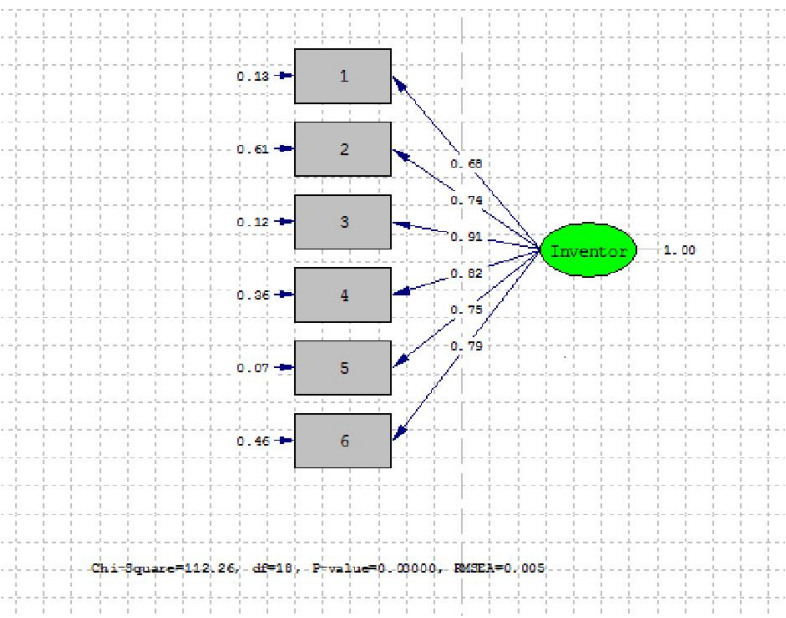

Standard coefficients

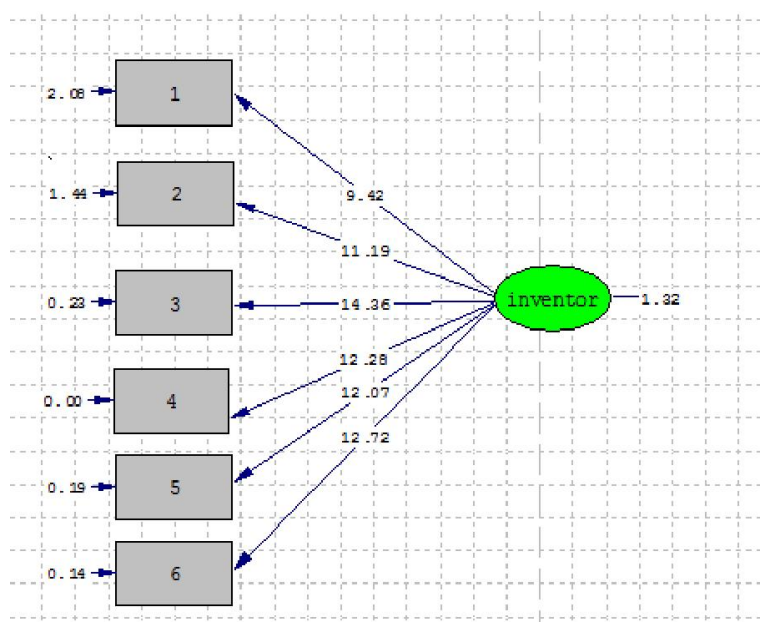

t-student values

Fig. 4. The results of outsourcing on inventory

One more time, Fig. 4 shows that all coefficients of the survey are statistically significant and tstudent values are meaningful for all questions. Therefore, we can confirm the effect of inventory.

\subsubsection{The effect of time}

Time is the last variable in our survey and Fig. 5 demonstrates details of our survey on this variable.

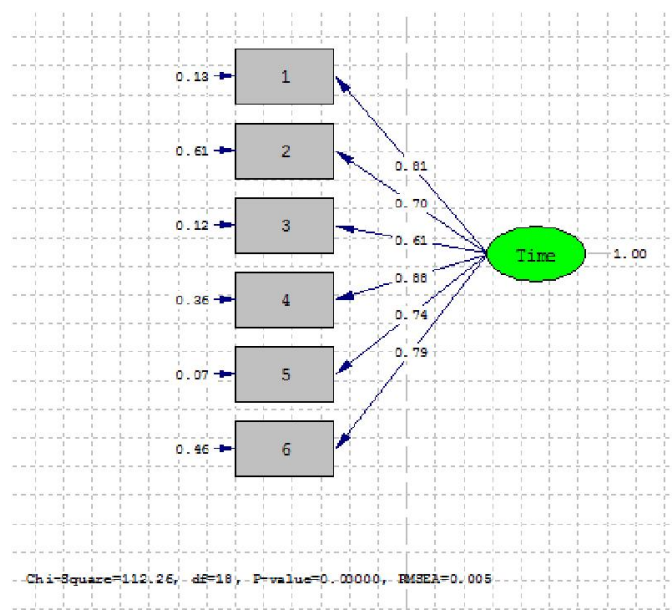

Standard coefficients

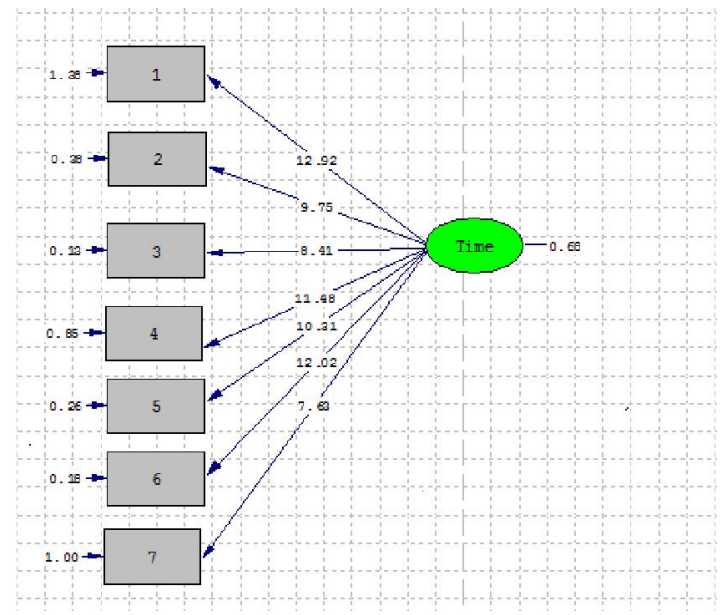

t-student values

Fig. 5. The results of outsourcing on time

Finally, Fig. 5 demonstrates that all coefficients of the survey are statistically significant and t-student values are meaningful for all questions. Therefore, we can confirm the effect of time.

\subsection{The effects of human capital, inventory and time}

We now consider the relationships of all three variables including human capital, inventory and time with outsourcing. Fig. 6 presents details of our findings. 


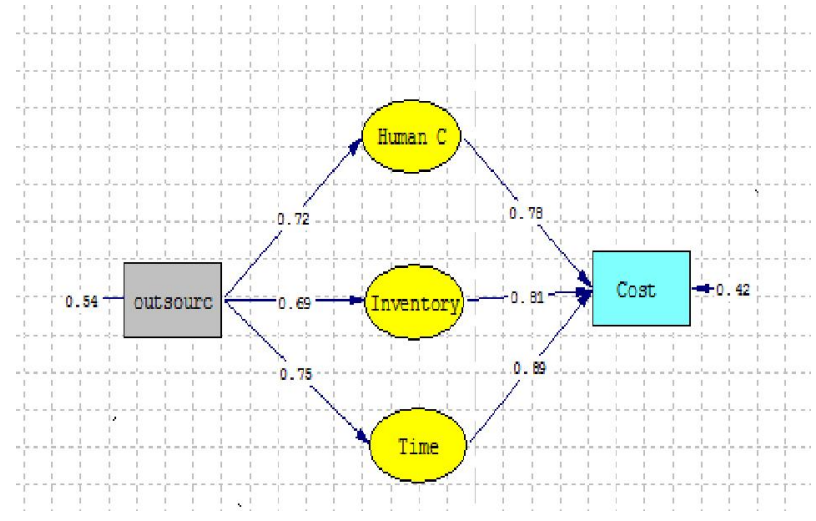

Fig. 6. The results of standard coefficients using structural equation modeling

\section{Discussion and conclusion}

As we see from the standard values of the implementation of structural equation modeling, there are some positive and meaningful relationships between human capital and outsourcing $(\beta=0.72)$, a positive relationship between inventory and outsourcing $(\beta=0.69)$, a positive relationship between time and outsourcing $(\beta=0.75)$ and all $t$-student values associated with these values are 8.91, 8.27 and 9.51, respectively. In addition, there are some positive and meaningful relationship between human capital and cost $(\beta=0.78$, t-value $=9.38)$, a positive and meaningful relationship between inventory and cost $(\beta=0.81, t$-value $=10.54)$ and a positive and meaningful relationship between time and cost $(\beta=0.89$, $t$-value $=11.26)$. These results confirm different hypotheses of the survey.

\section{References}

Arnold, U. (2000). New dimensions of outsourcing: a combination of transaction cost economics and the core competencies concept. European Journal of Purchasing \& Supply Management, 6(1), 2329.

Bahli, B., \& Rivard, S. (2003). The information technology outsourcing risk: a transaction cost and agency theory-based perspective. Journal of Information Technology, 18(3), 211-221.

Barthelemy, J., \& Geyer, D. (2001). IT outsourcing:: Evidence from France and Germany. European Management Journal, 19(2), 195-202.

Barthelemy, J. (2003). The seven deadly sins of outsourcing. The Academy of Management Executive, 17(2), 87-98.

Earl, M. J. (2012). The risks of outsourcing IT. Sloan management review, 37(3).

Gay, C. L., \& Essinger, J. (2000). Inside outsourcing. Nicholas Brealey Publishing.

Gilbert, S. M., Xia, Y., \& Yu, G. (2006). Strategic outsourcing for competing OEMs that face cost reduction opportunities. IIE Transactions, 38(11), 903-915.

Greer, C. R., Youngblood, S. A., \& Gray, D. A. (1999). Human resource management outsourcing: The make or buy decision. The Academy of Management Executive, 13(3), 85-96.

Kim, B. (2003). Dynamic outsourcing to contract manufacturers with different capabilities of reducing the supply cost. International Journal of Production Economics, 86(1), 63-80.

Lau, K. H., \& Zhang, J. (2006). Drivers and obstacles of outsourcing practices in China. International Journal of Physical Distribution \& Logistics Management, 36(10), 776-792.

Lee, J. N., Huynh, M. Q., Kwok, R. C. W., \& Pi, S. M. (2003). IT outsourcing evolution: past, present, and future. Communications of the ACM, 46(5), 84-89.

Maskell, P., Pedersen, T., Petersen, B., \& Dick-Nielsen, J. (2007). Learning paths to offshore outsourcing: from cost reduction to knowledge seeking. Industry and Innovation, 14(3), 239-257.

Rao, H. R., Nam, K., \& Chaudhury, A. (1996). Information systems outsourcing. Communications of the ACM, 39(7), 27-28. 